\title{
Cameroon English Speech: Intelligibility to Some Chinese Speakers of English Living in Cameroon and Pedagogic Concerns
}

\author{
Colvis Niba Ngwa \\ University of Yaounde I, Cameroon
}

\begin{abstract}
In the recent past, there have been several calls from Cameroonian scholars for the variety of English spoken within the country to be taught in the Cameroonian classroom, arguing strongly that the acquisition and use of Standard British English (SBE) is far-fetched given the socio-pragmatic realities of the context within which the language is learnt (see, for instance, Atechi, 2006; Ngefac, 2010 \& 2011). On the same token, there have been doubts whether Cameroon English (CamE) can be regarded as a variety in its own right (see Simo Bobda, 2002). This study set out to investigate the intelligibility of Cameroon English speech to educated Chinese speakers of English living in Cameroon and to examine what implications the findings can have on English Language teaching (ELT) in Cameroon.
\end{abstract}

Index Terms - Indigenisation, Intelligibility, ELT, Cameroon English Speech, Chinese English

\section{INTRODUCTION}

The spread of the English language across the globe has resulted in forms which are significantly different from those of the traditional seats of the language. This spread of the English language is very likely to lead to intelligibility problems within non-native varieties because the forms and the functions of the language differ from one context to another. Consequently, English is not used as a monolith in non-native settings as it is usually influenced by different sociolinguistic realities. It is in this light that we set out to investigate the intelligibility of a non-native English, that is CamE speech to speakers of educated Chinese speakers of English who themselves are non-native speakers living in Cameroon.

\section{CONCEPTUALISING INTELLIGIBILITY}

Intelligibility has attracted and sustained the interest of many researchers over the past decades. In fact, Atechi (2006) argues that "with the emergence of non-native varieties of English across the globe, the concept of intelligibility has attracted the sustained attention of many international scholars" (p. 1). Though intelligibility has occupied the nucleus of linguistic research for some time now, there seems to be no consensus among researchers as to what intelligibility is, as it has been viewed from wide-ranging perspectives. Kenworthy (1987) defines intelligibility as "being understood by a listener at a given time in a given situation." In more practical terms, she holds that "the more words a speaker is able to identify accurately, the more intelligible the speech is." Intelligibility, in this light, is defined in terms of the speaker and the listener in a particular speech interaction. Catford $(1950$, p 8$)$ holds that intelligibility depends on the effectiveness of an utterance. This effectiveness comes when the speaker's intention is understood by the listener. Thus, Catford (ibid) posits that any discussion of intelligibility must also deal with the loss of intelligibility. Munro and Derwing (1995a), on their part, define intelligibility as "the extent to which an utterance produced by a native speaker (NS) or non-native speaker (NNS) is understood by a native listener (NL) or non-native listener (NNL)." This definition dwells so much on the NS/ NNS dichotomy. It is worth noting here that studies in English have gone past the stage of the traditional definition of the native speaker. In fact, the distinction between native and non-native speaker may be considered archaic. After all, who defines a native speaker in a world where English has been adopted, adapted and nativised to suit context-specific realities? To rephrase this definition to suit the context of this study, we will look at intelligibility as the extent to which an utterance by a speaker is understood by a listener.

Far from defining what intelligibility is, some scholars (Smith 1992; Munro and Derwing 1995a; Munro et al., 2006) have rather looked at intelligibility as a component within a complex set of ideas. According to Smith (1992), the term "intelligibility" has a very broad sense; consequently, he divides it into three categories namely: intelligibility, comprehensibility and interpretability.

1. Intelligibility which focuses on word/ utterance recognition.

2. Comprehensibility which focuses on word/ utterance meaning.

3. Interpretability which focuses on meaning behind word/ utterance.

These three categories, as Smith (1992) argues, constitute a continuum and should be looked at as different. He classifies it in order of importance, from the least to the most important. Given that intelligibility entails understanding 
an utterance which can be achieved only through interpretation, this researcher shares Atechi's (2006, p. 43) view that, "this distinction seems not clear." This is because we cannot draw clear-cut lines on where one category ends and where another one begins. For instance, when a listener uses context and other clues to decode the speaker's message, we are dealing with aspects that go beyond simple word/ utterance recognition. Intelligibility, in this study, is perceived as the ability of a listener to accurately write down what a particular speaker has said.

\section{REVIEW OF LITERATURE}

Several studies on the intelligibility of non-native speech abound in the literature of the world Englishes. The intelligibility debate of non-native Englishes was triggered especially by the fact that most of NNEs have been regarded as "incorrect", "unacceptable" or "deviant." Some of these studies include Bansal (1969); Tiffen (1974); Munro and Derwing (1995); Munro (1998); Bradlow and Pisoni (1999); Jenkins (2002); van Wijngaarden (2001); van Wijngaarden et al. (2002) and Bent and Bradlow (2003). Jenkins (2002) examines the possible causes of communication breakdowns when NNSs communicate. In the study, she found out that "a combination of phonological errors which caused the most serious problems of intelligibility was as a result of wrongly placed stress in words" (p. 89). Thus, suprasegmental aspects of phonology cause a lot of intelligibility problems between non-native speakers. Pickering (2006), thus, qualifies non-native speakers in the light of their tonal structure (overuse of falling tones) as "unsympathetic and uninvolved." Stress and tone have proven to be major causes of intelligibility breakdown of non-native speech. Equally, according to Nash (1969), quoted in Bent and Bradlow (2003, p. 1601), "a non-native speaker who cannot make himself understood when speaking English to a native English speaker will have no difficulty conversing with another nonnative speaker." This suggests that non-native speech is more intelligible to other non-native speakers than to native speakers. Further research on the intelligibility of non-native speech, carried out by van Wijngaarden (2001), using native and non-native speakers, has provided very strong evidence to support this view; the findings reveal that nonnative listeners find sentences produced by non-native talkers as intelligible as those produced by native speakers. Nonnative talkers in this study were less intelligible than each of the four native talkers included.

Practically, the difficulty in understanding non-native speech has not only been subject to empirical studies but it has also been found in the difficulty native speakers find in understanding non-native speech in everyday communicative exchanges. A typical example is quoted by Atechi (2006, p. 53). As the report goes:

A Nigerian woman went to do her hair in a salon owned by an American lady of Jewish extraction.

The Nigerian, an English major from a famous Nigerian university, was of course sure of her English. She confidently articulated her needs in what she considers the Queen's English. Much to her chagrin, however, the only response she drew from the hairdresser was an apology, "I'm sorry, but I know no foreign language. I speak only English.

This anecdote captures the numerous dilemmas through which non-native speakers go when they interact with native speakers. Though this story may sound weird, it is worth noting that this very speech would have been perfectly intelligible to other non-native speakers, especially other Nigerians. This brings in the relevance of the question asked by previous researchers such as Kachru (1986), "intelligibility with whom?" Simo Bobda (1994, p. 14), in response to this question, points out that intelligibility is relative; it depends on the participants in the speech act, as well as on the context. In fact, Smith (1992) holds that we need to be intelligible only to those with whom we need to communicate. With the status of the English language today as a global language, where interaction is not only between native and non-native speakers but also among non-native speakers themselves, there is the dire need to investigate the extent to which non-native listeners can successfully understand other non-native speakers. In fact, it is within this framework that this study is situated.

If we chose to limit this study to the intelligibility of CamE speech, it is because CamE speech has been proven to be the highest aspect which posed intelligibility problems. This is supported by Ntumboh (1998) in her study on how Americans and British residing in Cameroon perceive English in terms of intelligibility. Though most of the informants held that CamE was very intelligible, a few, on the other hand, held that CamE was not intelligible at all. The study also revealed that more than $90 \%$ of the informants acknowledged that pronunciation was a major source of intelligibility problems as far as CamE is concerned.

In the light of the intelligibility studies, Atechi (2006) carried out a bi-directional study on the intelligibility of native and non-native Englishes. For the purpose of the study, five tests involving connected speech, phonemic contrast elicitation, passage reading, nucleus placement in words and sentences were conceived. Some aspects of native English were played to Cameroonian informants while CamE speech was played to Americans and British who were informants. The findings at the end of the investigation were summarised as follows:

1. When CamE speakers speak, native English speakers can understand about $61.3 \%$

2. When CamE speakers speak, BrE speakers can understand about $62.9 \%$.

3. When CamE speakers speak, AmE speakers can understand about 59.7\%

4. When native English speakers speak, CamE speakers can understand about $56.3 \%$

5. When BrE speakers speak, CamE speakers can understand about $58.7 \%$

6. When AmE speakers speak, CamE speakers can understand about 53.9\%

(Atechi 2006, p. 129) 
On the intelligibility of CamE speech which is the focus of this study, we discover that CamE speech is intelligible to $61.3 \%$ of the native speakers used for the study. More precisely, the statistics reveal that CamE speech was intelligible to $59.7 \%$ of British informants and $56.3 \%$ of Americans respectively. As Catford (1950, p. 8) puts it, we cannot look at intelligibility without looking at the other side of the coin. Thus, since this was a bi-dimensional study, the statistics presented above show that CamE speakers understand only about $56.3 \%$ of the speech of native speech. Well, we cannot belabour this point because the results go a long way to show the gap that exists between native and non-native speech. Thus, it equally reveals that CamE, in particular, has been so indigenised to the extent that it is no longer very intelligible to native speakers. Whatever the case, the overall results reveal that CamE is more intelligible to native speakers of English than native English is to the speakers of Cameroon.

On a whole, studies on CamE speech have revealed different levels of intelligibility of CamE speech and one thing which stands out clear in all the studies is that CamE speech is not $100 \%$ intelligible to the informants in the various studies. Equally, we discovered that most, if not, all of the studies had as informants native speakers. This, equally, reveals the dearth in the literature of the intelligibility of CamE speech from a non-native perspective. In a world where the non-native speakers are numerically superior to native speakers (Crystal 2003), such choice of informants has farreaching consequences as far as communication in the English language is concerned. Given the numerical advantage of non-native speakers, it is very likely that a CamE speaker when interacting with foreign speakers will interact more non-native speakers than native speakers.

\section{INTELLIGIBILITY TESTING}

A series of tests have been developed to investigate intelligibility. Kenworthy (1987) holds that the best way of testing intelligibility is through 'impressionistic' or 'subjective' assessments. In such assessments, a listener is asked to listen to a particular speaker and say how easy or difficult it is to understand them. She sees this method as not only accurate but also very reliable and, therefore, holds that "one does need complicated tests and procedures to assess the intelligibility of non- native speakers" (p. 20). However, this still poses a number of problems, the most pertinent being what a non-native speaker who wants to study the intelligibility of native speech to other non-native speakers do to if he/she cannot assemble the speakers and the listeners in a single place. Probably, it is due to such considerations that recent research on intelligibility (Atechi 2006; Nya 2010; Lugwig 2012) has tended to use tape recorders to record the speech of particular speakers. Tape recorders are advantageous in a number of ways: first, they assure accuracy and, second, they enable a researcher to test a particular speech pattern over long distances without having to carry the speakers of that variety along. With the increasing spread and use of the English language across the globe, it is worth noting that intelligibility studies have gone beyond mere word recognition, as illustrated by studies such as Bansal (1969); Tiffen (1974); Brown (1977); Atechi (2006); Chen (2011).

Other intelligibility studies have revealed a good number of intelligibility testing methods some of which are: doze procedure test (Smith \& Rafiqzad 1979), close tests (Nelson 1982), and translation form target language (TL) to L1 and vice versa. Thus, to test the intelligibility of CamE speech to the subjects under study, some tests have been designed. These tests will be read by selected speakers of CamE, after which, the speech will be recorded and played to the informants who will be expected to write down what they have heard. The results got are to be analysed and we will from the analysis, ascertain the degree of the intelligibility of CamE speech to educated Chinese speakers of English living in Cameroon.

\section{METHOD}

This study was carried out in the metropolitan cities of Yaounde and Bamenda. The study made use of both speakers and listeners. The speakers were Cameroonians who were to produce the sample speech to be used for the study. Thus, in order to get the speech sample for the study, a number of CamE speakers were observed and only those whose productions were representative of CamE speech were retained for the study. All the speakers were drawn from the faculty of Arts, Letters and Social Sciences of the University of Yaounde I. At first, some of the speakers were taken from the English Department but when their articulations were analysed, we discovered that most of the articulations were highly influenced by either RP or general American English. Equally, it was noticed that some of them tended to be too conscious of their speech that it led to forms that were not attested in any of the varieties (hypercorrection). Because of this, anyone who majored in English at the University was automatically disqualified as a speaker. So, five students of English speaking backgrounds were chosen and after a series of discussions with them, three were retained to produce the test material that could be presented to the informants.

The listeners, on the other hand, comprised fifty educated Chinese speakers of English residing either in the North West or Centre Regions of Cameroon. Education was an important consideration in the selection of the informants. This is because English is used in China to supplement the native Chinese language. Consequently, it is through formal education that most Chinese come in contact with English. In this light, 68\% of the informants had a Bachelor's Degree, while $32 \%$ had a Master's Degree in their different areas of specialisation.

In order to test the intelligibility of CamE speech to the informants above, a series of tests were designed to this effect. Consequently, the tests included word recognition. Consequently, some ten words which portrayed clear 
variations in pronunciation between Received Pronunciation (RP) and CamE speech were identified and adopted for the study. Apart from the identification of words in isolation, a passage was also designed by the researcher for the study. The usefulness of a passage to the testing of intelligibility is seen the fact that previous studies on intelligibility have proven that, when context is provided, words become more intelligible than when they are in isolation. Finally, the test material for testing intelligibility of CamE speech to the informants under study equally took into consideration some of the suprasegmental features of CamE, especially stress. Consequently, some words with deviant stress patterns were selected and subsequently put in these sentences. These tests were read out by CamE speakers, tape recorded by the researchers and, subsequently, played to the informants who were expected the write down what they had heard.

\section{RESULTS}

\section{A. The Intelligibility of Segmental Features of CamE Speech in Isolation}

These words analysed in this section were based exclusively on the segmental features of CamE speech. Hence, twelve words were carefully chosen and presented to the informants. The test reveals interesting scores on the intelligibility of segmental features of CamE speech. The scores were based on the ability of the subjects to identify tape-recorded words and write them correctly. A detailed account of the results of the intelligibility of the various words to the informants under study is presented on the table below.

TABLE I

THE DEGREE OF INTELLIGIBILITY OF SEGMENTAL FEATURES TO THE INFORMANTS

\begin{tabular}{|c|c|c|c|c|c|}
\hline No & Word & RP rendition & CamE rendition & Frequency of responses & Percentage \\
\hline 1 & Sergeant & /sadzont/ & /sedzent/ & 25 & 50 \\
\hline 2 & Colonel & /k3nəl/ & /kolonel/ & 18 & 36 \\
\hline 3 & Mayor & /meə/ & /mعjo/ & 23 & 46 \\
\hline 4 & Tower & /tavə/ & /towa/ & 25 & 50 \\
\hline 5 & Favourite & /fervrit/ & /fevorait/ & 40 & 80 \\
\hline 6 & Leopard & /lepəd/ & /ljopat/ & 4 & 16 \\
\hline 7 & Martyr & /matə/ & /mataja/ & 3 & 6 \\
\hline 8 & Sure & / /ృə/ & $/ \int \mathrm{j} /$ & 15 & 30 \\
\hline 9 & Tour & /tuə/ & $/ \mathrm{t} \mathrm{s} /$ & 18 & 36 \\
\hline 10 & Lawyer & /lэгә/ & /loja/ & 35 & 70 \\
\hline 11 & Assume & /osjum/ & /azjum/ & 45 & 90 \\
\hline \multirow[t]{2}{*}{12} & \multirow[t]{2}{*}{ Consume } & \multirow[t]{2}{*}{ /kənsjum/ } & /konzjum/ & 43 & 86 \\
\hline & & & Mean & 24.83 & 49.66 \\
\hline
\end{tabular}

Summarily, looking at the intelligibility situation of CamE speech basing our judgments from the analysis of the scores got from the informants' identification of words whose pronunciations have undergone different segmental modifications within the Cameroonian setting, we discover that the intelligibility situation is close to average as the mean percentage score for the test stands at $49.66 \%$. This means that if words are pronounced arbitrarily to Chinese speakers of English living in Cameroon, not up to half of the informants would be able to understand. Such results tell so much about the growth and development of CamE speech, especially at the segmental level and this has so many implications on the learning and use of the variety of English spoken in Cameroon. In the next section, we will look at the intelligibility situation of segmental features of words when used in continuous speech. Given that some of the words were also put in context, we will equally see how the inclusion of these words within specific contexts have improved or marred their intelligibility.

\section{B. The Intelligibility of Segmental Features of CamE Speech in Connected Speech}

In the analysis of this test, we paid keen interest on the role of context on some of the words discussed in the previous test. Such a method enabled us to bring out the various clues which enhance intelligibility. Given that this test was made up of a passage, we had to break it up into manageable segments to ease analysis. The intelligibility of CamE in connected speech is presented on the table below. 
TABLE II

THE INTELLIGIBILITY OF CONTINUOUS SPEECH TO THE INFORMANTS

\begin{tabular}{|c|c|c|c|}
\hline No. & Segment/sentence & Frequency of intelligible productions & Percentage \% \\
\hline 1. & Joan lives in a village in the southern part of the country & 5 & 10 \\
\hline 2. & Their division has a police station & 35 & 70 \\
\hline 3. & and a local council with a mayor at its head & 20 & 40 \\
\hline 4. & It also has a clinic which takes care of amoeba infections. & 5 & 10 \\
\hline 5. & $\begin{array}{l}\text { Though they assume that they have a plumber who is in charge of their } \\
\text { water supply, }\end{array}$ & 28 & 56 \\
\hline 6. & they always consume infected water. & 23 & 46 \\
\hline 7. & Last December, there was a serious bombing of the post office tower & 15 & 30 \\
\hline 8. & The colonel, who was head of the military & 20 & 40 \\
\hline 9. & opted for to be a martyr & 5 & 10 \\
\hline 10. & when he decided to challenge the terrorists with his old sword & 25 & 50 \\
\hline 11. & Though he was not sure to win & 33 & 66 \\
\hline 12. & his colleagues constantly surveyed the whole area & 15 & 30 \\
\hline \multirow[t]{2}{*}{13.} & making it difficult for the invaders to escape. & 33 & 66 \\
\hline & Mean & 20.15 & 40.30 \\
\hline
\end{tabular}

The table above shows that the mean intelligibility score for this test stands at $40.30 \%$. This therefore suggests that aspects of CamE pronunciation in connected speech pose some problems of understanding to educated Chinese speakers of English living in Cameroon. The very fact that segmental aspects of CamE pronunciation are intelligible to less than $50 \%$ of the population under study goes a long way to confirm postulations of previous studies on CamE (Simo Bobda and Mbangwana 1993, Simo Bobda 1994) that CamE has developed a quasi-autonomous phonological system. In the next section, we will look at the intelligibility of some suprasegmental aspects of CamE speech to the population under study.

\section{The Intelligibility of Suprasegmental Features of Came Speech}

In line with the objectives of this study, we also sought to find out the degree to which suprasegmental features of CamE speech were intelligible to the population under study. This is because when we speak, we use both segmental and suprasegmental features of pronunciation concomitantly. Consequently, we designed a test in which we used words whose stress patterns deviate significantly from RP, but are used normally in CamE speech. Though this test was made up on sentences, we focused our analysis on the rendition of the words concerned. The written productions of the informants were analysed and the degree to which they were intelligible is presented on the following table.

TABLE III

THE INTELLIGIBILITY OF SUPRASEGMENTAL FEATURES TO THE INFORMANTS

\begin{tabular}{|c|c|c|c|c|}
\hline No & RP stress position & CamE stress position & $\begin{array}{l}\text { Frequency of correct } \\
\text { answers }\end{array}$ & Percentage \\
\hline 1 & 'classificatory & classifi'catory & 26 & 52 \\
\hline 2 & 'mandatory & man'datory & 25 & 50 \\
\hline 3 & 'tentative & ten'tative & 28 & 56 \\
\hline 4 & 'plantains & Plan'tains & 25 & 50 \\
\hline 5 & se'conds & 'seconds & 20 & 40 \\
\hline 6 & re'cord (verb) & 'record & 25 & 50 \\
\hline 7 & suc'cess & 'success & 23 & 46 \\
\hline 8 & um'brella & 'umbrella & 30 & 60 \\
\hline 9 & op'ponent & 'opponent & 20 & 40 \\
\hline \multirow[t]{2}{*}{10} & \multirow[t]{2}{*}{ 'subjected } & sub'jected & 45 & 90 \\
\hline & & Mean & 26.7 & 53.4 \\
\hline
\end{tabular}

The analysis of the suprasegmental features of CamE with focus on stress shows that its mean percentage score is $53.4 \%$. This therefore suggests that, in some cases, the stress position of a word in CamE speech may significantly influence the rate of intelligibility of a word or segment. However, on a whole, we can postulate that stress does not really pose intelligibility problems as this test was intelligible to more than half of the population.

\section{The Intelligibility of CamE Rhythm}

Generally, rhythm is the succession of stressed and unstressed sounds in a language, resulting in particular beats. Thus, rhythm depends largely on stress. So, deviant stress patterns from those to which the listener is accustomed to can result in a rhythm that can cause problems of intelligibility to the listeners. Wirth noting here is the fact that the rhythm of CamE speech significantly deviates from that of RP because CamE pronunciation is made up of strong forms where almost every syllable is stressed. Thus, given that the tests, especially that to test the intelligibility of stress to the informants under study was intelligible to $53.4 \%$ of the informants, we can infer that CamE rhythm does not really impair intelligibility given that rhythm is generally defined by stress placement.

\section{IMPLICATIONS OF FINDINGS AND CONCLUSION}

The relationship between intelligibility and aspects of speech production is a very complicated one. This is because 
the spread of the English language across different areas has met with so many cultures that have significantly influenced its pronunciation, as it is being adopted and adapted to suit context-specific realities. Thus, the English language spoken in the Cameroonian context is not left out as it has equally undergone significant indigenisation, thereby leading to a new variety of English known in linguistic literature today as CamE. However, though the variety has developed extensively to capture the worldview of its speakers, it has not been recognised in the classroom. Consequently, ELT in Cameroon still targets SBE, in spite of numerous calls from scholars (Ngefac 2010, 2011; Atechi 2010, Ngwa 2015) for the recognition and use of CamE in the classroom. The fact that SBE is still targeted as the goal for ELT in Cameroon raises many problems in the classroom because the teachers themselves are non-native speakers who cannot squarely teach SBE without the interference of CamE on their lessons. Hence, it is worth noting that SBE, which is the target of ELT in Cameroon, is almost inexistent and, consequently, there is the need to get learners acquainted with the variety of English spoken in Cameroon. Drawing from our findings, we noted that segmental features were not very intelligible to the informants under study as the mean intelligibility score stood at less than $50 \%$. Given that the informants themselves are non-native speakers of English, such results suggest that, even within nonnative contexts, the English language is fast spreading and is taking new forms. Consequently, ELT material in Cameroon should be tailored to meet the new changes the language is embracing in Cameroon.

With regard to shaping ELT material to suit the context-specific realities of its new environment, we do not ignore the fact that there are worries or questions which really need to be clarified. These include the material to use in teaching and the purpose for which the language is learned. As far as ELT in Cameroon is concerned, most scholars argue that SBE will always be dominant because it is well codified and there exist so many visual and audio-visual tools to ease the acquisition of the variety. The primary claim here is that the native or older varieties of English dominate the ELT industry because of the fact that it has a huge database on them which enhance the learning of the English language. However, the problem with not using CamE in the classroom does not really lie with the unavailability of material on the subject because CamE has been described at all linguistic levels and this literature shows the CamE has fairly predictable and stable features, especially at the phonological level. In fact, Ngwa (2015, p. 27) sees the acceptance of non-native Englishes in ELT as "a way to facilitate the process of codification, which will guarantee fairly stable non-native standards that can help in the process of looking for solutions to the intelligibility problems raised." Thus, teaching CamE will not only enhance the codification of the language but will also lead to the standardisation of the language since only the stable features will be identified and taught. The real problem lies with stakeholders who need to change attitudes and accept the fact that CamE is robust enough to capture the cosmic visions of its speakers. Consequently, it should not be relegated to the background.

Having analysed the findings got on the intelligibility of CamE speech, it can be deduced that the most appropriate premise from which to treat the complex notion of intelligibility within the Cameroonian setting, especially in the classroom, is arguably the fact that, first of all, it must tie with the function of the English language in Cameroon which is the immediate context of the adaptation of the language. This is because Cameroonians use English more for national than international needs. Hence, this too should be reflected in the classroom. Deviating from previous studies which have investigated the complex relationship between intelligibility and features of SBE, this study has focused on the intelligibility of CamE speech to non-native speakers from the Expanding Circle. The findings have revealed that with a little bit of effort from both the Cameroonians and Chinese when they engage in conversations, comfortable intelligibility can be achieved. Thus, as far as the teaching of CamE is concerned, we can adopt Bamgbose's (1971, p. 41) view, quoted in Simo Bobda (1994), of a local variety that will satisfy the minimum requirements of national and international intelligibility.

\section{REFERENCES}

[1] Atechi, S. N. (2006). The Intelligibility of Native and Non-Native English Speech. Gottingen: Cuvillier Verlag.

[2] Atechi, S. N. (2010). "The Plurality of English in Cameroon and the International Intelligibility Question." Syllabus Review, 1(2), pp. 199- 218.

[3] Bamgbose, A. (1971). “The English Language in Nigeria,” In Spencer (1971), 35-48.

[4] Bansal, R. K. (1969). The Intelligibility of Indian English. Monograph 4, Hyderabad: Central Institute of English and Foreign Languages.

[5] Bradlow A. R. and Bent T. (2003). "The Interlanguage Speech Intelligibility Benefit." Journal of the Acoustical Society of America, 114(3), 1600-1610.

[6] Bradlow, A. R., and Pisoni, D. B. (1999). "Recognition of spoken words by native and non-native listeners: Talkers, listeners, and item-related factors," Journal of Acoustical Society of America. 106, 2074-2085.

[7] Brown, A. (1989). "Some thoughts on intelligibility" The English Teacher Vol XVIII

[8] Brown, G. (1977). Listening to Spoken English. London: Longman

[9] Catford, J.C. (1950). "Intelligibility" English Language Teaching 5:7-15.

[10] Crystal, D. (2003). English as a Global Language. 2nd ed. Cambridge: Cambridge University Press.

[11] Derwing, T. M. and Munro, M. J. (2001). What speaking rates do non-native listeners prefer? Applied Linguistics, 22, $324-337$.

[12] Jenkins, J. (2002). “A Sociolinguistically Based, Empirically Researched Pronunciation Syllabus for English as an International Language." Applied Linguistics, 23(1) 83-103.

[13] Kachru, B. B. (1986). The Alchemy of English: The Spread, Functions and Models of Non-Native Englishes. Oxford: Pergamon Press. 
[14] Kenworthy, J. (1987). Teaching English Pronunciation. London: Longman.

[15] Ludwig, A. (2012). "Interlanguage Speech Intelligibility Benefit for Non-Native Listeners." Unpublished Master's Thesis: University of Barcelona.

[16] Munro, M. and Derwing, T. (1995a). "Foreign Accent, Comprehensibility, and Intelligibility in the Speech of Second Language Learners." Language learning, 45, 73-97.

[17] Munro, M.; Derwing, T. and Morton, S. (2006). "The mutual intelligibility of L2 speech." Studies in Second Language Acquisition, 28, 111- 131.

[18] Nash, R. (1969). "Intonational Interference in the Speech of Puerto Rican Bilinguals," Journal of English 4, 1-42.

[19] Ngefac, A. (2010). "Cameroon English Accent: Issues of Standardization, Attitudes and Pedagogic Concerns.” Journal of Languages and Culture. Vol. 1(1), pp. 1-7.

[20] Ngefac, A. (2011). "When the Blind Lead the Blind: the Fallacy of Promoting Standard British English Accent in Cameroon." Journal of Language Teaching and Research, Vol. 2, No. 1, pp. 40-44.

[21] Ngwa, C. N. (2015). "Basilectal Forms of CamE Speech". DIPES II dissertation, ENS Yaounde.

[22] Ntumboh, Eunice. (1998). "Use of Correct English in semi Urban Areas, Native speakers perception of, and Attitudes Towards CamE Pronunciation.” DIPEN II dissertation, ENS Yaounde.

[23] Nya, C. F. (2010). "The intelligibility of some Basilectal forms of Cameroon English to both Cameroonians and Westerners." Unpublished Post Graduate dissertation, ENS, Yaoundé.

[24] Pickering, L. (2006). "Current research on Intelligibility in English as a Lingua Franca." Annual review of applied linguistics. Cambridge university press, 26, 219-233

[25] Simo Bobda, A. (1994). Aspects of Cameroon English Phonology. Peter Lang, Inc.; European Academic Publishers, Bern.

[26] Simo Bobda, A. and P. Mbangwana (1993). An Introduction to Spoken English. Lagos: Lagos University Press.

[27] Smith, L.E. and Rafiqzad, K. (1979). "English for cross-cultural communication: the question of Intelligibility." TESOL Quarterly 13:371-380.

[28] Smith, L.E. (1992). "Spread of English and issues of Intelligibility,” in B. B. Kachru (ed.) (1992). The Other Tongue. Urbana and Chicago: University of Illinois Press.

[29] Tiffen, B. (1974). "The Intelligibility of Nigerian English.” Unpublished PhD Thesis, University of London.

[30] Van Wijngaarden, S. J. (2001). "Intelligibility of native and non-native Dutch speech." Speech Commun. 35, 103-113.

[31] Van Wijngaarden, S. J., Steeneken, H. J. M., and Houtgast, T. (2002). "Quantifying the intelligibility of speech in noise for non-native listeners." Journal of the Acoustical Society of America. 111, 1906-1916.

Ngwa Colvis Niba holds a Master's Degree in English Language from the University of Yaounde 1, Cameroon, where he is currently completing a thesis on the mutual intelligibility of non-native Englishes, with focus on Cameroon English and Tanzanian English. He is a graduate assistant in English at the Higher Teacher Training College, Bertoua under the University of Ngaoundere where he has been teaching many language and research-related courses for the past three years. He has presented papers at different conferences organised by the Universities of Yaounde and Bamenda. 